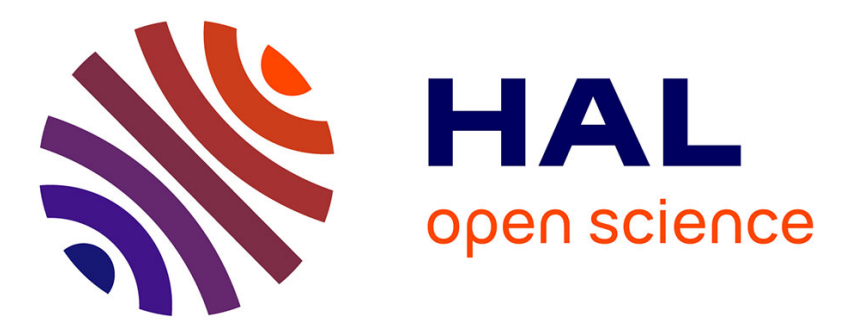

\title{
La2Ga3O7.5: a metastable ternary melilite with a super-excess of inter- stitial oxide ions synthesized by direct crystallization of the melt
}

Jintai Fan, Vincent Sarou-Kanian, Xiaoyan Yang, Maria Diaz-Lopez, Franck Fayon, Xiaojun Kuang, Michael J Pitcher, Mathieu Allix

\section{To cite this version:}

Jintai Fan, Vincent Sarou-Kanian, Xiaoyan Yang, Maria Diaz-Lopez, Franck Fayon, et al.. La2Ga3O7.5: a metastable ternary melilite with a super-excess of inter- stitial oxide ions synthesized by direct crystallization of the melt. Chemistry of Materials, 2020, 32 (20), pp.9016-9025. 10.1021/acs.chemmater.0c03441 . hal-02959774

\section{HAL Id: hal-02959774 \\ https://hal.science/hal-02959774}

Submitted on 7 Oct 2020

HAL is a multi-disciplinary open access archive for the deposit and dissemination of scientific research documents, whether they are published or not. The documents may come from teaching and research institutions in France or abroad, or from public or private research centers.
L'archive ouverte pluridisciplinaire HAL, est destinée au dépôt et à la diffusion de documents scientifiques de niveau recherche, publiés ou non, émanant des établissements d'enseignement et de recherche français ou étrangers, des laboratoires publics ou privés. 


\title{
$\mathrm{La}_{2} \mathrm{Ga}_{3} \mathrm{O}_{7.5}$ : a metastable ternary melilite with a super-excess of inter- stitial oxide ions synthesized by direct crystallization of the melt
}

\author{
Jintai Fan, ${ }^{1,2}$ Vincent Sarou-Kanian, ${ }^{1}$ Xiaoyan Yang, ${ }^{3}$ Maria Diaz-Lopez, ${ }^{4,5}$ Franck Fayon, ${ }^{1}$ Xiaojun \\ Kuang, ${ }^{3,6}$ Michael J. Pitcher ${ }^{1 *}$ and Mathieu Allix ${ }^{{ }^{*}}$ \\ ${ }^{1}$ CNRS, CEMHTI UPR3079, 45071 Orléans, France \\ ${ }^{2}$ Shanghai Institute of Optics and Fine Mechanics, Chinese Academy of Science, Shanghai, 201800, P. R. China \\ ${ }^{3}$ Guangxi Key Laboratory of Optical and Electronic Materials and Devices College of Materials Science and Engineering, \\ Guilin University of Technology, Guilin 541004, P. R. China \\ ${ }^{4}$ ISIS Facility, STFC Rutherford Appleton Laboratory, Didcot, OX11 0QX, UK \\ ${ }^{5}$ Diamond Light Source, Diamond House, Harwell Science and Innovation Campus, Didcot OX11 0QX, UK \\ ${ }^{6}$ College of Chemistry and Bioengineering, Guilin University of Technology, Guilin 541004, P. R. China
}

\begin{abstract}
The $\mathrm{La}_{1+\mathrm{x}} A E_{1-\mathrm{x}} \mathrm{Ga}_{3} \mathrm{O}_{7+\mathrm{x} / 2}$ melilite family $(A E=\mathrm{Ca}$, $\mathrm{Sr}$, Ba, and $0 \leq \mathrm{x} \leq 0.64)$ demonstrates remarkable oxide ion conductivity due to the ability of its layered tetrahedral $\left[\mathrm{Ga}_{3} \mathrm{O}_{7+\times / 2}\right]$ network to accommodate and transport interstitial oxide ions $\left(\mathrm{O}_{\text {int }}\right)$. Compositions $\mathrm{x}>0.65$ with very high $\mathrm{O}_{\text {int }}$ concentrations (referred to here as "super-excess" compositions) have the potential to support correspondingly high ionic conductivities, but have never before been accessed due to the limitations of conventional solidstate ceramic synthesis. Here we report that fully-substituted $\mathrm{La}_{2} \mathrm{Ga}_{3} \mathrm{O}_{7.5}(\mathrm{x}=1)$ melilite ceramics can be synthesized by direct crystallization of an under-cooled melt, demonstrating that super-excess compositions are accessible under suitable nonequilibrium reaction conditions. $\mathrm{La}_{2} \mathrm{Ga}_{3} \mathrm{O}_{7.5}$ is stable up to $830^{\circ} \mathrm{C}$ and exhibits an ionic conductivity of $0.01 \mathrm{~S} . c m^{-1}$ at $800{ }^{\circ} \mathrm{C}$, three orders of magnitude higher than the corresponding $\mathrm{x}=0$ end-member $\mathrm{LaSrGa}_{3} \mathrm{O}_{7}$, and close to the range exhibited by the current best-in-class $\mathrm{La}_{1.54} \mathrm{Sr}_{0.46} \mathrm{Ga}_{3} \mathrm{O}_{7.23}\left(0.1 \mathrm{~S} . c m^{-1}\right)$. It crystallizes in an orthorhombic $\sqrt{2} a \times \sqrt{2} a \times 2 c$ expansion of the parent melilite cell, in space group Ima2, with full long-range ordering of $\mathrm{O}_{\text {int }}$ into chains within the $\left[\mathrm{Ga}_{3} \mathrm{O}_{7.5}\right]$ layers. The emergence of this chain-like (1D) ordering within the 2D melilite framework, which appears to be an incipient feature of previously reported partially-ordered melilites, is explained in terms of the underlying hexagonal topology of the structure. These results will enable the exploration of extended compositional ranges for the development of new solid oxide ion electrolytes with high concentrations of interstitial oxide charge carriers.
\end{abstract}

The discovery of new compounds with high oxide ion conductivities is important for the development of solid oxide fuel cell (SOFC) technology, where it is desirable to reduce device operating temperatures to the range $500-800^{\circ} \mathrm{C}$ to improve durability and reduce running costs. ${ }^{1,2}$ However, it can be challenging to access new compositions using classic ceramic synthesis routes, because the high temperatures and extended heating times required tend to favour the formation of thermodynamic products. This means that potential metastable compositions and structures, which may be highly stable at the temperatures of interest for their function, can be missed. Aerodynamic levitation (ADL) coupled to laser heating ${ }^{3,4}$ offers routes to new metastable bulk oxides by the crystallization-from-glass method, where a glass precursor is fabricated by rapid quenching of a congruent melt and then crystallised by annealing above the glass transition temperature, or by direct crystallisation of the under-cooled melt. Both routes have recently emerged as useful processes for the non-equilibrium synthesis of new bulk oxides in the form of high-density low-porosity ceramics, ${ }^{5-9}$ and are amenable to chemistries that support interstitial oxide ion conductivity, as demonstrated recently for gallate- ${ }^{8}$ and aluminate-based ${ }^{10}$ melilites and the scheelite-type bismuth vanadates. $^{11}$
The melilite structure has been of interest for potential SOFC applications since the first reports of high ionic conductivity in non-stoichiometric $\mathrm{La}_{1+\mathrm{x}} \mathrm{Sr}_{1-\mathrm{x}} \mathrm{Ga}_{3} \mathrm{O}_{7+\mathrm{x} / 2 .}{ }^{12}$ Its structure (general formula $A_{2} B_{3} \mathrm{O}_{7}$ ) consists of a two-dimensional framework of corner-sharing 3- and 4-connected $\mathrm{BO}_{4}$ tetrahedra forming distorted pentagonal channels perpendicular to the stacking axis, which alternates with a layer of $A$ cations in 8-fold coordination by oxide ions. In $\mathrm{La}_{1+\mathrm{x}} A E_{1-\mathrm{x}} \mathrm{Ga}_{3} \mathrm{O}_{7+\mathrm{x} / 2}\left(A E=\mathrm{Ca}^{2+}, \mathrm{Sr}^{2+}\right.$ or $\left.\mathrm{Ba}^{2+}\right)$, interstitial oxide ions $\left(\mathrm{O}_{\text {int }}\right)$ are incorporated into the framework close to the centres of the pentagonal rings by tuning the $\mathrm{La}^{3+} / A E^{2+}$ ratio (x). ${ }^{13}$ This creates $\mathrm{GaO}_{5}$ trigonal bipyramidal units locally by coordination of $\mathrm{O}_{\text {int }}$ to gallium ions within the tetrahedral layer, which is stabilized by a substantial bonding contribution from the two adjacent $\mathrm{La}^{3+} / \mathrm{Sr}^{2+}$ cations. ${ }^{14,15}$ At elevated temperatures, these interstitial oxide ions act as chargecarriers, primarily by diffusion within the Ga-O framework layer. ${ }^{16,17}$ Consequently, the ionic conductivity $(\sigma)$ depends directly on the concentration of interstitial oxide $(\mathrm{x})$ in the framework. In $\mathrm{La}_{1+\mathrm{x}} A E_{1-\mathrm{x}} \mathrm{Ga}_{3} \mathrm{O}_{7+\mathrm{x} / 2}\left(A E=\mathrm{Ca}^{2+}, \mathrm{Sr}^{2+}\right), \sigma$ shows a strong increase with $\mathrm{x}$, and reaches a broad maximum of $\sim 0.1 \mathrm{Scm}^{-1}$ at $800^{\circ} \mathrm{C}$ when $0.5 \leq \mathrm{x} \leq 0.6 .{ }^{17-19}$ At higher concentrations $(0.60$ $<\mathrm{x} \leq 0.65$ for $A E=\mathrm{Sr}^{2+}$ and $0.55 \leq \mathrm{x} \leq 0.64$ for $\left.A E=\mathrm{Ca}^{2+}\right)$, the onset of long-range oxide ordering induces an orthorhombic distortion, which is associated with a slight decrease in $\sigma .{ }^{19}$ The 
compositional limit of the solid solution is finally reached at $\mathrm{x}$ $=0.65$ : above this limit, single-phase melilite samples cannot be obtained from $A E=\mathrm{Ca}^{2+}, \mathrm{Sr}^{2+}$ by ceramic synthesis. ${ }^{18,19} \mathrm{~A}$ similar trend in ionic conductivity with increasing $\mathrm{x}$ is observed in $\mathrm{La}_{1+\mathrm{x}} \mathrm{Ba}_{1-\mathrm{x}} \mathrm{Ga}_{3} \mathrm{O}_{7+\mathrm{x} / 2}$, which has a smaller compositional stability range of $0 \leq x<0.35$ and remains tetragonal throughout the series. ${ }^{20}$

In all three series, the maximum observed interstitial oxide concentration $(x=0.65)$ is substantially lower than the proposed saturation value of the framework at $x=1$, based on the consideration of local strain effects in the Ga-O layer, ${ }^{18}$ which would correspond to full substitution of $A E$ by $\mathrm{La}^{3+}$. This implies that the structure may be amenable to further enrichment with interstitial oxide if suitable thermodynamic routes can be identified. The ability to break through this limit to super-excess $\mathrm{O}_{\text {int }}$ concentrations $0.65<\mathrm{x} \leq 1$ would substantially increase the explorable phase space in this class of compounds, raising the prospect of further improvements in conductivity and new structural chemistry. Recent studies suggest that non-equilibrium synthesis methods can be used to exceed such compositional limits. For example, a sol-gel approach with annealing at moderate temperatures drastically extends the accessible interstitial oxide concentration range in langasite-type $\mathrm{La}_{3} \mathrm{Ga}_{5-\mathrm{x}} \mathrm{Ge}_{1+\mathrm{x}} \mathrm{O}_{14+\mathrm{x} / 2}$, ${ }^{.1}$ whilst the synthesis of metastable melilites including the nonstoichiometric aluminates $\mathrm{La}_{1+\mathrm{x}} \mathrm{Ca}_{1-\mathrm{x}} \mathrm{Al}_{3} \mathrm{O}_{7+\mathrm{x} / 2}(\mathrm{x} \leq 0.6)$ and $\mathrm{a}$ range of stoichiometric and nonstoichiometric small-A-site compositions, which cannot be achieved by high temperature ceramic routes, is made possible by crystallization-fromglass. ${ }^{8,10,22}$

A recent study of (1-y) $\mathrm{La}_{2} \mathrm{O}_{3}-(\mathrm{y}) \mathrm{Ga}_{2} \mathrm{O}_{3}$ glasses by ADL-laser heating found that $\mathrm{y}=0.40$ was difficult to vitrify despite lying well within the limits of the glass-forming region $(0.20 \leq \mathrm{y} \leq$ $0.55)$, hinting at the presence of an unknown metastable compound. ${ }^{23}$ Motivated by the potential for a non-equilibrium route to super-excess melilites, we describe here the synthesis of the previously unknown ternary compound $\mathrm{La}_{2} \mathrm{Ga}_{3} \mathrm{O}_{7.5}(\mathrm{y}=0.40)$ and its structural and physical characterisation. We found that this compound forms in a single step by rapid direct crystallisation of the under-cooled melt, and adopts a new fully-ordered melilite superstructure with a chain-like arrangement of interstitial oxide ions. $\mathrm{La}_{2} \mathrm{Ga}_{3} \mathrm{O}_{7.5}$, the $\mathrm{x}=1$ end member of the $\mathrm{La}_{1+\mathrm{x}} A E_{1-\mathrm{x}} \mathrm{Ga}_{3} \mathrm{O}_{7+\mathrm{x} / 2}$ interstitial oxide conductor family, is stable up to $830^{\circ} \mathrm{C}$ and retains a high oxide ion conductivity, suggesting that long-range oxide ion ordering is only moderately detrimental to electrolyte performance and opening the door to the exploration of a new range of melilite compositions.

\section{EXPERIMENTAL}

Synthesis procedure. High-purity $\mathrm{La}_{2} \mathrm{O}_{3}$ powder (STREM $99.99 \%$, pre-dried at $1100{ }^{\circ} \mathrm{C}$ for 12 hours in air) and $\mathrm{Ga}_{2} \mathrm{O}_{3}$ powder (STREM, 99.999\%) were weighed according to the molar ratio $39 \mathrm{La}_{2} \mathrm{O}_{3}-61 \mathrm{Ga}_{2} \mathrm{O}_{3}$ (where the excess of $\mathrm{Ga}_{2} \mathrm{O}_{3}$ compared to the target composition $\mathrm{La}_{2} \mathrm{Ga}_{3} \mathrm{O}_{7.5}$ was used to compensate for vaporization during the laser heating steps). The $\mathrm{La}_{2} \mathrm{O}_{3}$ and $\mathrm{Ga}_{2} \mathrm{O}_{3}$ powders were mixed in an agate mortar under ethanol, then dried at $100{ }^{\circ} \mathrm{C}$ to remove residual ethanol. The dry powder was then pressed into pellets under $20 \mathrm{MPa}$ uniaxial pressure. Pellet fragments of $\sim 30 \mathrm{mg}$ were placed into the conical nozzle of the aerodynamic levitator system. ${ }^{3,24,25}$ The samples reported in this work were heated by a pair of $\mathrm{CO}_{2}$ lasers while levitating in a flow of oxygen gas, with temperature mon- itored in-situ by an IR pyrometer. Melting of the reaction mixture occurred at approximately $1650{ }^{\circ} \mathrm{C}$, and the samples were further heated up to $1800{ }^{\circ} \mathrm{C}$ for several seconds to homogenize the melt. The temperature was then decreased to $1500^{\circ} \mathrm{C}$ before switching off the lasers, thus quenching the samples to room temperature. The occurrence of direct crystallization of the melt was indicated by an intense flash from the cooling bead. This heating and quenching process was repeated several times until the beads adopted a homogeneous transparent appearance (see Figure S1). No further heat treatment was applied to the quenched beads. The beads were then either crushed and ground into powders for structural characterization, or were optically polished with an automatic polisher on silicon carbide papers to a thickness of approximately $1 \mathrm{~mm}$ for conductivity measurements.

Our attempts to synthesize high quality samples of $\mathrm{La}_{2} \mathrm{Ga}_{3} \mathrm{O}_{7.5}$ by low temperature glass-crystallization were unsuccessful due to the difficulty in vitrifying compositions close to $39 \mathrm{La}_{2} \mathrm{O}_{3}-$ $61 \mathrm{Ga}_{2} \mathrm{O}_{3}$. Further details, including the crystallization behavior of the strongly Ga-deficient glasses that we obtained (Figures $\mathrm{S} 2$ and S3), are provided in the Supporting Information.

Powder Diffraction. Provisional phase identification and indexing was conducted using a Bruker D8 Advance diffractometer with $\mathrm{Cu} \mathrm{K} \alpha$ radiation in Bragg-Brentano mode. Variable temperature PXRD (VT-PXRD) data were recorded during heating from room temperature up to $850{ }^{\circ} \mathrm{C}$ under air using a HTK1200N Anton Paar furnace. The powder sample was placed in a platinum-lined corundum sample holder. Data were collected from $12-70^{\circ}(2 \theta)$ with a $0.016^{\circ}$ step size and an acquisition time of $0.5 \mathrm{~s}$ per step. The evolution of the unit cell parameters was obtained from Le Bail refinements.

For combined synchrotron powder X-ray diffraction (SPD) and neutron powder diffraction (NPD) experiments a large $(\sim 5 \mathrm{~g})$ powder sample of $\mathrm{La}_{2} \mathrm{Ga}_{3} \mathrm{O}_{7.5}$ was prepared by crushing and combining a large number of individual beads. SPD data were collected at 11-BM at the Advanced Photon Source, Argonne National Laboratory, U.S.A. The sample was contained in a Kapton capillary of inner diameter $0.8 \mathrm{~mm}$. Data were collected from a spinning sample $(60 \mathrm{~Hz})$ over the $0.5-50^{\circ} 2 \theta$ range with a $0.001^{\circ}$ step size and acquisition duration of $0.1 \mathrm{~s}$ per step at room temperature with $\lambda=0.412737 \AA$. NPD experiments were carried out at the D2B high-resolution/high-flux powder diffractometer at the Institut Laüe-Langevin in Grenoble, France. The samples were packed in vanadium cans and data were acquired with $\lambda=1.594 \AA$ at $2 \theta$ intervals of $0.05^{\circ}$ over the $10^{\circ}<$ $2 \theta<160^{\circ}$ angular range. The structure of the sample was refined using a combination of SPD and NPD data using the Rietveld method implemented in Jana2006. ${ }^{26}$ Bond valence sum maps were calculated using BondStr. ${ }^{27}$

X-ray total scattering data were collected at the I15-1 beamline at the Diamond Light Source, UK, using $\lambda=0.161669 \AA$ (76.7 $\mathrm{keV})$. A sample of $\mathrm{La}_{2} \mathrm{Ga}_{3} \mathrm{O}_{7.5}$ was contained in a borosilicate glass capillary with an inner diameter of $1 \mathrm{~mm}$ and measured for several minutes at room temperature using a Perkin Elmer area detector placed $\sim 200 \mathrm{~mm}$ downstream from the sample. The position of the sample was calibrated with a Si standard and the collected 2D X-ray scattering data was processed into 1D patterns using the DAWN software. ${ }^{28}$ The data were corrected using equivalent measurements taken from an empty capillary and Fourier-Transformed using the GudrunX software with $\mathrm{Q}_{\max }=25 \AA^{-1}$. A simultaneous Rietveld and pair distribution 
function (PDF) refinement using the same model was performed with TOPAS v. $6 .{ }^{29}$ An $r$-dependent function of the thermal parameters as implemented in TOPAS v.6 was used to fit the data within the range 1.5-50 $\AA$, where the $B_{\text {iso }}$ of all atoms were constrained to match those in Rietveld for $r \geq 20 \AA$.

Calculations. Density Functional Theory (DFT) calculations with periodic boundary conditions were performed with the CASTEP code ${ }^{30,31}$ using the Materials Studio 7.0 interface. The PBE functional ${ }^{32}$ was used to describe electron exchange-correlation effects. Core-valence interactions were described by ultrasoft pseudopotentials generated on-the-fly. ${ }^{33}$ Geometry optimization was performed using the BFGS minimization method $^{34}$ and fixing the cell parameters to experimental values. Electric field gradient (EFG) and NMR chemical shift tensors computations were carried out for the experimentally refined structural models using the projector-augmented waves $(\mathrm{PAW})^{35}$ and gauge included PAW (GIPAW) ${ }^{36}$ algorithms, respectively. A kinetic energy cutoff of $600 \mathrm{eV}$ was used for the plane wave basis set expansion and the Brillouin zone was sampled using a Monkhorst-Pack grid spacing of $0.04 \AA^{-1}$ (corresponding to a k-point mesh of $3 \times 3 \times 3$ ). The ${ }^{71} \mathrm{Ga}$ isotropic chemical shifts $\left(\delta_{\mathrm{ISO}}\right)$ were deduced from calculated isotropic shielding values $\left(\sigma_{\mathrm{ISO}}\right)$ using the relation $\delta_{\mathrm{ISO}}=-0.912 \sigma_{\mathrm{ISO}}+1519$, which accounts for systematic errors on computed values using this method. This relationship was obtained from the linear regression between experimental $\delta_{\text {ISO }}$ and calculated $\sigma_{\text {ISO }}$ values for seven crystalline gallium-containing compounds of known structures (see Table S1 and Figure S5). For all reference compounds, computations were performed without DFT-geometry optimization using the same parameters as those described above. For structural models, $1 \times 2 \times 1$ supercells were used (containing 200 atoms). DFT optimization of the atomic positions and cell parameters and total energy computations were performed using ultrasoft pseudopotentials requiring lower energy cutoff of $380 \mathrm{eV}$ with a Monkhorst-Pack grid spacing of 0.04 $\AA^{-1}$ (corresponding to a k-point mesh of $2 \times 1 \times 2$ ).

Solid-state Nuclear Magnetic Resonance. We selected ${ }^{71} \mathrm{Ga}$ (nuclear spin $\mathrm{I}=3 / 2$ ) as the NMR-active nucleus due to the large quadrupolar broadenings of ${ }^{69} \mathrm{Ga}(\mathrm{I}=3 / 2)$ and ${ }^{139} \mathrm{La}(\mathrm{I}=$ $7 / 2)$, and the low abundance of ${ }^{17} \mathrm{O}(\mathrm{I}=5 / 2)$. ${ }^{71} \mathrm{Ga}$ solid-state NMR experiments were performed on a Bruker Avance Neo spectrometer operating at $20.0 \mathrm{~T}\left({ }^{71} \mathrm{Ga}\right.$ Larmor frequency of $259.3 \mathrm{MHz}$ ) with a $0.7 \mathrm{~mm}$ magic angle sample spinning (MAS) double-resonance probehead. The MAS frequency was set to $100 \mathrm{kHz}$ to avoid overlap between the central transition (CT) centre band and its associated spinning sidebands. The 1D quantitative CT-selective ${ }^{71} \mathrm{Ga}$ spectrum was recorded using a Hahn-echo experiment with acquisition at the echo top using an inter-pulse delay of $20 \mu \mathrm{s}$. The radio frequency (RF) field was $125 \mathrm{kHz}$ to ensure a selective and homogenous excitation of the whole CT spectral range (90- and 180-degree pulse durations of 1.0 and $2.0 \mu \mathrm{s}$, respectively). The $2 \mathrm{D}$ double-quantum filtered (DQF-) STMAS spectrum ${ }^{37,38}$ was recorded using an RF field of $420 \mathrm{kHz}$ for the excitation and mixing pulses with pulse durations of $0.4 \mu \mathrm{s}$ and $0.3 \mu \mathrm{s}$, respectively. For the DQ filter and readout pulses the RF-field was $125 \mathrm{kHz} .124$ rotor synchronized $t_{1}$-increments with 4864 transients each were recorded with a recycle delay of $0.25 \mu \mathrm{s}$. The magic angle was carefully set by first performing a ${ }^{23} \mathrm{Na} 2 \mathrm{D}$ DQF-STMAS experiment on a polycrystalline $\mathrm{NaH}_{2} \mathrm{PO}_{4}$ sample. ${ }^{71} \mathrm{Ga}$ chemical shifts were referenced relative to a $1.1 \mathrm{M}$ aqueous solution of $\mathrm{Ga}\left(\mathrm{NO}_{3}\right)_{2}$. All spectra were reconstructed using the Dmfit software. ${ }^{39}$
AC Impedance Spectroscopy. Impedance spectroscopy measurements were carried out with a Solartron 1260 frequency response analyzer over the $10^{-1}-10^{7} \mathrm{~Hz}$ frequency range within $300-800{ }^{\circ} \mathrm{C}$. Platinum paste was coated on the opposite faces of the polished disks and fired at $600{ }^{\circ} \mathrm{C}$ for $30 \mathrm{~min}$ to burn out the organic components to form electrodes. The impedance data analysis was carried out using the ZView software.
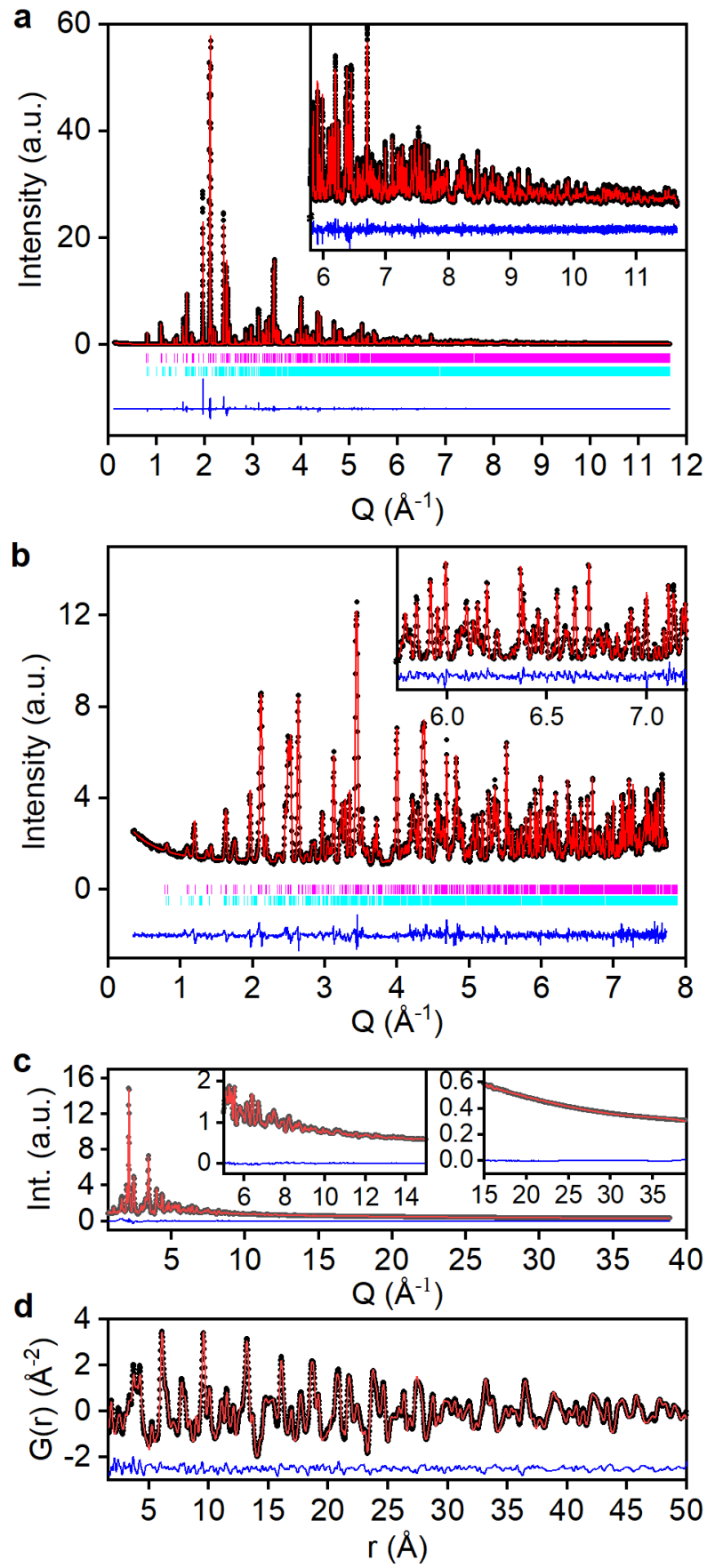

Figure 1. Structural refinements of $\mathrm{La}_{2} \mathrm{Ga}_{3} \mathrm{O}_{7.5}$ in Ima2. (a,b) Combined Rietveld refinement against SPD data from 11BM, and NPD data from D2B, with the fits to the high-Q regions inset. (c,d) Simultaneous Rietveld and PDF fit against SPD data from I15-1. Magenta ticks $=\mathrm{La}_{2} \mathrm{Ga}_{3} \mathrm{O}_{7.5}$, cyan ticks $=\mathrm{La}_{4} \mathrm{Ga}_{2} \mathrm{O}_{9}(\sim 2 \mathrm{wt} \%)$. Black points $=$ yobs, red line $=$ ycalc, blue line $=$ yobs - ycalc. 


\section{RESULTS AND DISCUSSION}

Synthesis and Crystal Structure. Laboratory PXRD on crushed beads of $\mathrm{La}_{2} \mathrm{Ga}_{3} \mathrm{O}_{7.5}$ synthesised by direct crystallisation of the under-cooled melt produced a new diffraction pattern that did not correspond to any mixture of known compounds, but closely resembled that of the pseudo-orthorhombic melilite $\mathrm{La}_{1.64} \mathrm{Ca}_{0.36} \mathrm{Ga}_{3} \mathrm{O}_{7.32}$ reported by Li et. al. ${ }^{18}$ (see Figure $\mathrm{S} 1$ ). Compositional analysis of a polished crystalline bead by SEMEDX showed a $\mathrm{Ga} / \mathrm{La}$ ratio of $1.51(1)$, consistent with $\mathrm{La}_{2} \mathrm{Ga}_{3} \mathrm{O}_{7.5}$. Together, these results suggest that the crystalline beads of $\mathrm{La}_{2} \mathrm{Ga}_{3} \mathrm{O}_{7.5}$ contain a new phase whose structure is derived from melilite.

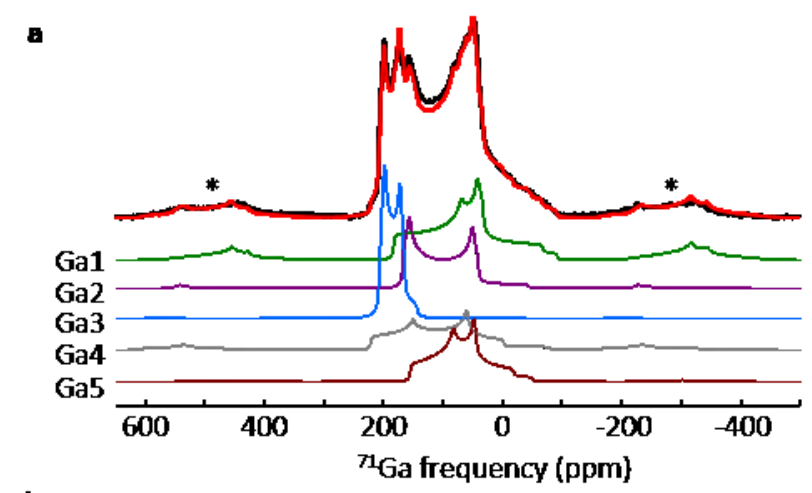

b

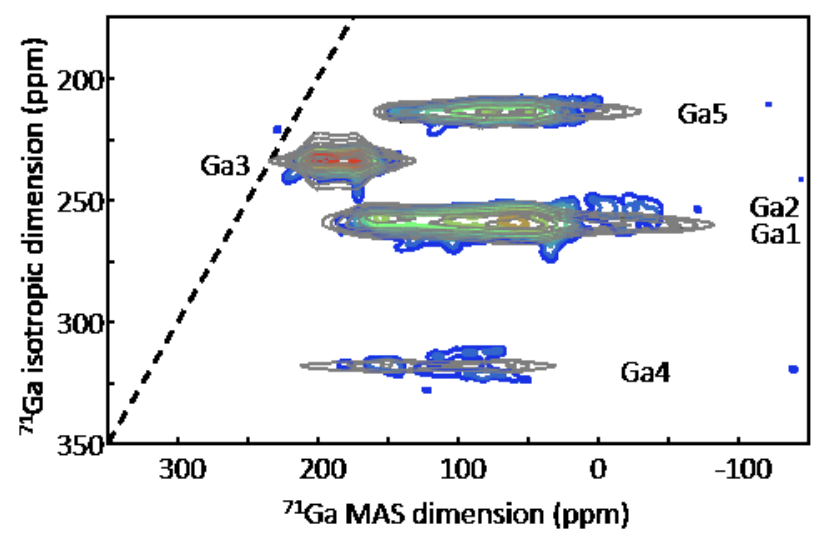

Figure 2: (a) Experimental (black) and reconstructed (red) ${ }^{71} \mathrm{Ga}$ quantitative CT MAS spectra of $\mathrm{La}_{2} \mathrm{Ga}_{3} \mathrm{O}_{7.5}$ recorded at $20.0 \mathrm{~T}$ with a spinning frequency of $100 \mathrm{kHz}$. The asterisks indicate spinning sidebands. The five individual ${ }^{71} \mathrm{Ga}$ resonances are shown below. (b) Experimental (colored contours) and reconstructed (gray contours) DQF STMAS spectra obtained at $20.0 \mathrm{~T}$ with a spinning frequency of $100 \mathrm{kHz}$ evidencing the five distinct ${ }^{71} \mathrm{Ga}$ resonances.

Structural analysis was performed using SPD data and constantwavelength neutron diffraction (NPD) data simultaneously. To generate a provisional structural model for $\mathrm{La}_{2} \mathrm{Ga}_{3} \mathrm{O}_{7.5}$, we used the published pseudo-orthorhombic $(P 1)$ structure of $\mathrm{La}_{1.64} \mathrm{Ca}_{0.36} \mathrm{Ga}_{3} \mathrm{O}_{7.32}{ }^{18}$ as a template. This had the double advantage of providing a good approximation of the underlying melilite framework and the oxide interstitial sites, without imposing symmetry constraints on the possible interstitial oxide ion orderings. We then performed a Rietveld refinement, allowing the atomic coordinates (52 independent atoms) to refine, along with the fractional occupancies of the interstitial oxide sites and three independent isotropic displacement parameters (one for each atom type $\mathrm{La}, \mathrm{Ga}, \mathrm{O}$ ). Additionally, $\mathrm{La}_{4} \mathrm{Ga}_{2} \mathrm{O}_{9}$ was included as a secondary phase (note that this phase was only observed in the large-scale sample prepared for SPD-NPD combined refinement, at $\sim 2 \mathrm{wt} \%$ ). This preliminary refinement produced a good fit to both data sets and revealed a distinct ordering of the interstitial oxides into chains (see Figure S4 for Rietveld fits and Table S2 for refined parameters). Having established a provisional model in this way, we sought to minimise the number of refined structural parameters in the model by performing a DFT optimisation of all atomic positions with lattice parameters fixed to experimental values, followed by a symmetry search. This transformed the structure into a new orthorhombic unit cell in space group Ima2, whose lattice parameters correspond to a $\sqrt{ } 2 a \times \sqrt{ } 2 a \times 2 c$ expansion of the tetragonal parent melilite unit cell. This model, which indexes both the SPD and NPD patterns correctly, contains 18 atoms in the asymmetric unit ( $v s .50$ in the provisional $P 1$ model, Table S2) including 5 crystallographically inequivalent Ga atoms (vs. 12 in $P 1)$.

To confirm the space group assignment, we probed the number of crystallographically inequivalent Ga sites in the structure by using high-resolution solid-state NMR with ${ }^{71} \mathrm{Ga}(\mathrm{I}=3 / 2)$ as the active nucleus. ${ }^{40,41}$ As shown in Figure 2, the ${ }^{71}$ Ga central-transition (CT) magic angle spinning (MAS) spectrum recorded at $20.0 \mathrm{~T}$ with a spinning frequency of $100 \mathrm{kHz}$ exhibits a complex line shape revealing the presence of several overlapping ${ }^{71} \mathrm{Ga}$ resonances that are strongly affected by second-order quadrupolar effects. We therefore used a 2D double-quantum filtered (DQF) ST-MAS ${ }^{38}$ experiment to improve the spectral resolution by removing the second-order quadrupolar broadening in an indirect dimension. This allowed five distinct ${ }^{71} \mathrm{Ga}$ resonances to be resolved unambiguously, two of them (Ga1 and Ga2) with very close isotopic frequencies being discriminated by their different ${ }^{71} \mathrm{Ga}$ isotropic chemical shifts and second-order quadrupolar coupling parameters. The relative intensities of the resonances were obtained by fitting the quantitative CT MAS spectrum using the ${ }^{71} \mathrm{Ga}$ chemical shift and quadrupolar coupling parameters determined from the DQF-STMAS spectrum. This showed that the five resonances have relative intensities in the ratio $2: 1.03: 0.96: 1.05: 0.96$, in full agreement with Ima2 symmetry for which the five crystallographically inequivalent Ga sites have a multiplicity ratio of $2: 1: 1: 1: 1$. On this basis, we consider that symmetry lowering to $P 1$ (leading to 12 inequivalent Ga sites of equal multiplicity) is not required.

The final Rietveld refinement was carried out simultaneously against NPD and SPD data starting from the DFT-optimised Ima 2 model. As shown in Figure 1(a,b), this produced good fits to both data sets $\left(R_{w p}=7.49 \%, \chi^{2}=3.06\right.$, which are nearly identical to the agreement factor $\chi^{2}=2.98$ obtained in $P 1$, as shown in Figure S4). The refined structure (final lattice parameters $a=$ 11.4701(4) $\AA, b=11.2674(4) \AA, c=10.4804(4) \AA)$ is illustrated in Figure 3. To verify the model's reliability on the local scale, we conducted a simultaneous Rietveld-PDF fit against X-ray total scattering data (I15, Diamond Light Source, UK) using the Ima2 Rietveld model with fixed atomic coordinates. As shown in Figure 1(c,d), this provided a good fit to G(r) including over short distances of $<5 \AA\left(R_{w p}=2.75 \%\right)$. Finally, GIPAW ${ }^{36}$ DFT calculations of ${ }^{71} \mathrm{Ga}$ NMR parameters were performed for the refined Ima 2 model. This produced calculated ${ }^{71} \mathrm{Ga}$ isotropic chemical shifts and quadrupolar coupling parameters that are consistent with the experimentally observed values (see Table $1)$. 
Table 1: Experimental and GIPAW-DFT calculated (italic) ${ }^{71} \mathrm{Ga}$ isotropic chemical shifts $\left(\delta_{\mathrm{CS}}{ }^{\mathrm{ISO}}\right)$, quadrupolar coupling constant $\left(\mathrm{C}_{\mathrm{Q}}\right)$, asymmetry parameter $\left(\eta_{\mathrm{Q}}\right)$ of the quadrupolar coupling tensor and relative intensities (I) for the Rietveld-refined Ima 2 structural model. Calculated isotropic chemical shifts were deduced from calculated isotropic shieldings $\left(\sigma_{\mathrm{CS}}{ }^{\mathrm{ISO}}\right)$ using the relation $\delta_{\mathrm{CS}}{ }^{\mathrm{ISO}}=-0.912 \sigma_{\mathrm{CS}}{ }^{\mathrm{ISO}}+$ 1519 (ppm). Experimental and GIPAW-calculated (italic) peak positions in the STMAS isotropic dimension $\left(\delta\right.$ sTMAS $\left.^{\text {ISO }}\right)$ for a spin-3/2 nucleus are given as $\delta_{\mathrm{STMAS}}{ }^{\mathrm{ISO}}=\delta_{\mathrm{CS}} \mathrm{ISO}_{+} \frac{1}{17} \frac{10^{6}}{v_{0}^{2}}\left(\frac{c_{Q}}{2}\right)^{2}\left(1+\frac{\eta_{\mathrm{Q}}^{2}}{3}\right)$, where $v_{0}$ is the ${ }^{71}$ Ga Larmor frequency $(259.4 \mathrm{MHz}) .{ }^{37,42} \mathrm{The}$ quadrupolar coupling parameters are defined as $\mathrm{CQ}_{\mathrm{Q}}=\frac{\mathrm{eQ}\left|\mathrm{V}_{\mathrm{ZZ}}\right|}{h}$ and $\eta_{\mathrm{Q}}=\left|\frac{\mathrm{V}_{\mathrm{YY}-}-\mathrm{V}_{\mathrm{XX}}}{\mathrm{V}_{\mathrm{ZZ}}}\right|$ where $\mathrm{Q}$ is the ${ }^{71} \mathrm{Ga}$ nuclear quadrupole moment, e is the electron charge, $h$ is the Plank constant and $V_{i i}$ are the principal components of the EFG tensor at the Ga site (V.m²) with $\left|V_{X X}\right|<\left|V_{Y Y}\right|<\left|V_{Z Z}\right|$. For each Ga site, the coordination polyhedron and its number of bridging oxygen atoms (BO) forming short Ga-O-Ga bonds are given.

\begin{tabular}{|c|c|c|c|c|c|c|c|c|c|c|}
\hline Site & Mult. & Coordination & BO & & $\begin{array}{l}\delta \mathrm{Cs}^{\mathrm{ISO}} \\
(\mathrm{ppm})\end{array}$ & $\begin{array}{l}\sigma_{\mathrm{CS}}{ }^{\mathrm{ISO}} \\
(\mathrm{ppm}) \\
\end{array}$ & $\begin{array}{c}\left|\mathrm{C}_{\mathbf{Q}}\right| \\
(\mathrm{MHz}) \\
\end{array}$ & $\eta_{Q}$ & $\begin{array}{c}\delta_{\text {STMAS }}{ }^{\text {ISO }} \\
(\mathrm{ppm})\end{array}$ & I (\%) \\
\hline \multirow[t]{2}{*}{ Ga1 } & 4 & $\mathrm{GaO}_{4}$ & 3 & Exp. & 187.0 & 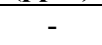 & 16.40 & 0.80 & 258.0 & 33.3 \\
\hline & & & & Calc. & 197.0 & 1449.6 & 15.18 & 0.87 & 260.1 & 33.33 \\
\hline \multirow[t]{2}{*}{$\mathrm{Ga} 2$} & 2 & $\mathrm{GaO}_{4}$ & 4 & Exp. & 198.5 & - & 16.10 & 0.08 & 255.0 & 17.2 \\
\hline & & & & Calc. & 199.9 & 1446.4 & 14.05 & 0.11 & 243.2 & 16.67 \\
\hline \multirow[t]{2}{*}{ Ga3 } & 2 & $\mathrm{GaO}_{4}$ & 4 & Exp. & 214.0 & - & 8.60 & 0.20 & 230.5 & 16.0 \\
\hline & & & & Calc. & 229.6 & 1413.8 & 8.02 & 0.21 & 243.8 & 16.67 \\
\hline \multirow[t]{2}{*}{$\mathrm{Ga} 4$} & 2 & $\mathrm{GaO}_{4}$ & 3 & Exp. & 240.0 & - & 18.30 & 0.40 & 317.0 & 17.5 \\
\hline & & & & Calc. & 241.2 & 1401.1 & 12.99 & 0.56 & 282.0 & 16.67 \\
\hline \multirow[t]{2}{*}{ Ga5 } & 2 & $\mathrm{GaO}_{5}$ & 3 & Exp. & 160.3 & - & 14.51 & 0.65 & 213.0 & 16.0 \\
\hline & & & & Calc. & 150.9 & 1500.1 & 13.27 & 0.30 & 190.5 & 16.67 \\
\hline
\end{tabular}
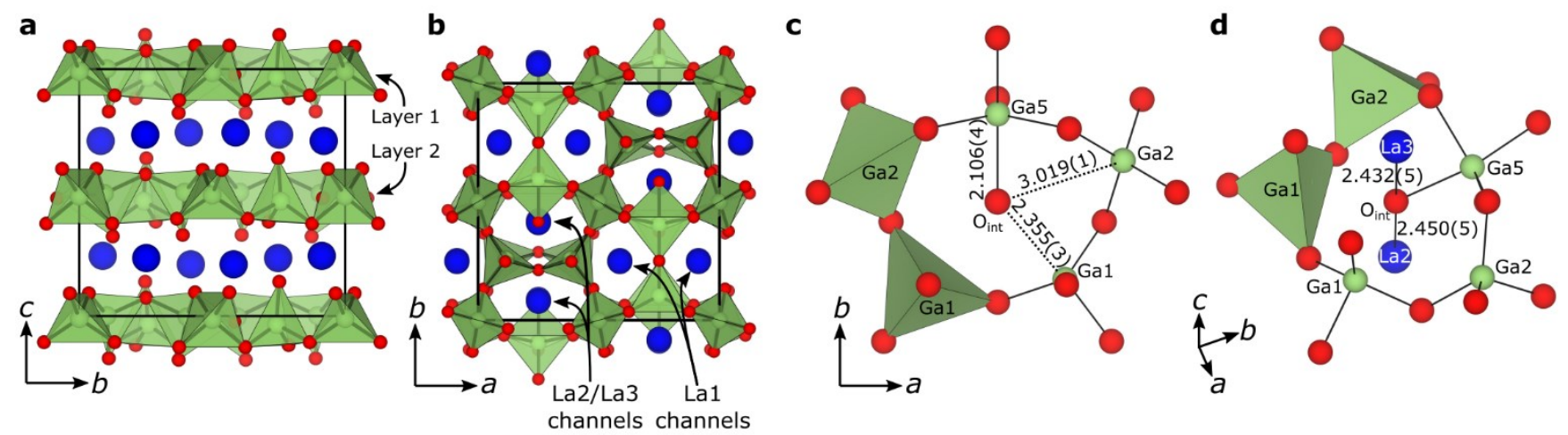

e

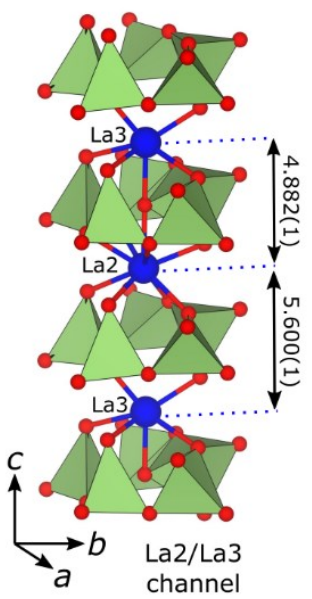

f

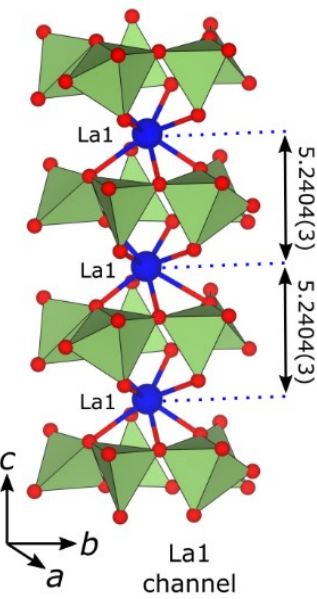

g

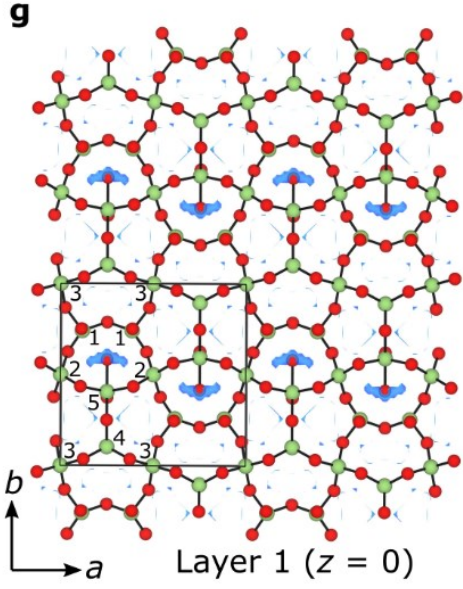

$\mathbf{h}$

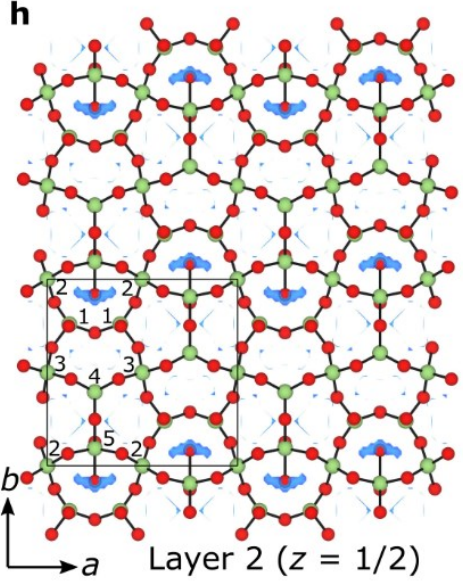

Figure 3. Refined crystal structure of $\mathrm{La}_{2} \mathrm{Ga}_{3} \mathrm{O}_{7.5}$ in $\operatorname{Ima} 2$. (a,b) Unit cell projections along the $a$ - and $c$-axes $\left(\right.$ blue $=\mathrm{La}^{3+}$, green $=\mathrm{Ga}^{3+}$, red $\left.=\mathrm{O}^{2-}\right)$. (c,d) Local coordination environment of the interstitial oxide at the centres of the pentagonal rings, labelled with distances (in $\AA$ ) for the nearest O-Ga and O-La contacts. (e,f) The two distinct channel types labelled with their inter-layer La-La distances (in $\AA$ ), showing a periodic short/long alternation in the interstitial-hosting channels (the La2/La3 channels) which is commensurate with the interstitial oxide ordering, in contrast to the regular La-La spacing in the "empty" channels (the La1 channels). (g,h) calculated BVS maps for $\mathrm{O}^{2-}$, sliced 
through the Ga plane of layers 1 and 2, showing the relaxation of the framework to accommodate $\mathrm{O}^{2-}$ in chains along the $a$-axis, which are staggered along the stacking axis $c$. Blue surfaces correspond to BVS values between -1.8 and -2.2 . The crystallographically independent Ga sites are labelled with numbers 1-5.

The refined structure of $\mathrm{La}_{2} \mathrm{Ga}_{3} \mathrm{O}_{7.5}$ retains the topology of the

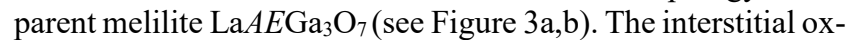
ide ions $\left(\mathrm{O}_{\text {int }}\right)$ are incorporated entirely into the $\left[\mathrm{Ga}_{3} \mathrm{O}_{7.5}\right]$ layer, which is constructed from a fully-ordered corner-sharing network of $\mathrm{GaO}_{4}$ tetrahedra and $\mathrm{GaO}_{5}$ trigonal bipyramids in a 5:1 ratio. As in the parent structure, the $\left[\mathrm{Ga}_{3} \mathrm{O}_{7.5}\right]$ framework forms pentagonal channels along the stacking axis. The $\mathrm{La}^{3+}$ cations occupy the inter-layer space, where each is aligned to the centre of a pentagonal channel. This provides a suitable coordination environment for the interstitial oxide close to the centres of the channels (Figure 3c,d) where it is stabilised by significant bonding contributions from three neighbouring cations: a pair of short contacts to $\mathrm{La}^{3+}$ ions from the adjacent layers $\left(\mathrm{La} 2-\mathrm{O}_{\text {int }}=\right.$ $2.432(5) \AA$ and $\left.\mathrm{La} 3-\mathrm{O}_{\text {int }}=2.450(5) \AA\right)$, and a short contact to the $\mathrm{Ga}^{3+}$ at the apex of the pentagon to form a $\mathrm{GaO}_{5}$ unit $\left(\mathrm{Ga} 5-\mathrm{O}_{\text {int }}\right.$ $=2.016(4) \AA)$. These are supplemented by a pair of longer contacts to $\mathrm{Ga}^{3+}\left(\mathrm{Ga} 1-\mathrm{O}_{\text {int }}=2.355(3) \AA\right)$, and together these five contacts provide a calculated bond valence sum (BVS) of -1.81 , with $\mathrm{La}-\mathrm{O}$ and $\mathrm{Ga}-\mathrm{O}$ contacts making a near-equal contribution. These bonding contributions between $\mathrm{O}_{\text {int }}$ and $\mathrm{Ga}^{3+}$ cations are reflected in ${ }^{71} \mathrm{Ga}$ chemical shift trends: the Ga4 site $\left(\delta_{\text {ISO }} \sim 240\right.$ ppm) which is coordinated by 3 bridging (BO) and 1 non-bridging oxygen (NBO) atoms is shifted toward higher frequency with respect to the $\mathrm{Ga} 2(\sim 198 \mathrm{ppm})$ and $\mathrm{Ga} 3$ sites ( $214 \mathrm{ppm})$ which exhibit $4 \mathrm{Ga}-\mathrm{O}-\mathrm{Ga}$ bridging bonds, as is expected since these $3 \mathrm{Ga}$ sites are at remote distance from $\mathrm{O}_{\text {int }}$. In contrast, the Ga5 site with $3 \mathrm{BO}, 1 \mathrm{NBO}$ and an additional short contact to $\mathrm{O}_{\text {int }}$ exhibits an isotropic chemical shift of $\sim 160$ ppm typical of $\mathrm{GaO}_{5}$ units. The $\mathrm{Ga} 1-\mathrm{O}_{\text {int }}$ longer contact supplementing 3 bridging and 1 non-bridging bonds also leads to a significant shift toward lower frequency of the Ga1 site $\left(\delta_{\text {ISO }} \sim 187 \mathrm{ppm}\right)$ relative to the Ga4 resonance. This mode of interstitial coordination is
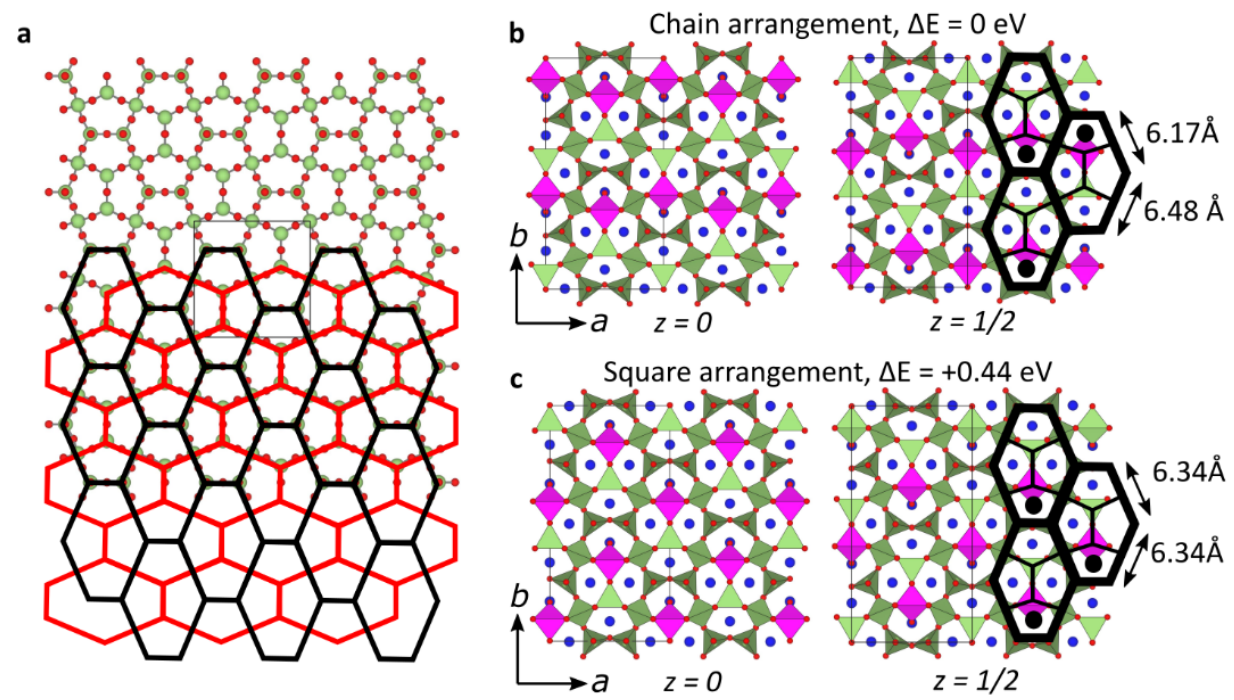

consistent with that observed in $\mathrm{La}_{1+\mathrm{x}} A E_{1-\mathrm{x}} \mathrm{Ga}_{3} \mathrm{O}_{7+\mathrm{x} / 2 .}{ }^{14,18,20}$ All of the $\mathrm{O}_{\text {int }}$ sites are symmetrically equivalent. By calculating an $\mathrm{O}^{2-} \mathrm{BVS}$ map from the refined structure, and searching for regions with BVS values between $1.8-2.2$ (shown as slices through the $\left[\mathrm{Ga}_{3} \mathrm{O}_{7.5}\right]$ layers in Figure $3 \mathrm{~g}, \mathrm{~h}$ ) it can be seen that these regions coincide only with the fully-occupied $\mathrm{O}_{\text {int }}$ sites; the structure is distorted such that the unoccupied channels to not offer viable alternative coordination sites for $\mathrm{O}_{\text {int }}$.

In contrast to the $\mathrm{x} \leq 0.65$ melilites, $\mathrm{La}_{2} \mathrm{Ga}_{3} \mathrm{O}_{7.5}$ exhibits complete long-range ordering of $\mathrm{O}_{\text {int }}$ both within and between the layers. Within the layers, the occupied pentagonal rings form infinite vertex-linked chains which run parallel to the $a$-axis (Figure 3g,h). Each unit cell contains one chain per layer, so that the intra-layer distance between chains is equal to the $b$ parameter (11.2674(4) $\AA$ ). Between the layers, the chains are staggered to produce a 2 -fold expansion of the $c$-axis relative to the tetragonal parent melilite. The staggering originates from interlayer ordering within the pentagonal channels: two distinct channel types can be identified and categorised as half-occupied (the La2/La3 channels, as shown in Figure 3e) or unoccupied (the La1 channels, Figure $3 \mathrm{f}$ ) by $\mathrm{O}_{\text {int, }}$ with each unit cell containing four of each channel type. The occupancy of $\mathrm{O}_{\text {int }}$ in the La2/La3 channels alternates between layers such that each occupied $\mathrm{O}_{\text {int }}$ has a pair of empty neighbours. The alternation in $\mathrm{O}_{\text {int }}$ occupancy is coupled to an alternation in the inter-layer LaLa distance: this provides the short La-La distance (4.882(1) $\AA$ ) required for the local coordination of $\mathrm{O}_{\text {int }}$, and an alternating long La-La distance (5.600(1) $\AA$ ) which traverses the empty adjacent sites. In contrast, the unoccupied channels (La1, Figure 3f), which have no such local coordination requirements, exhibit a regular La-La distance of 5.2404(3) $\AA$ (=c/2).

Figure 4. DFT comparison of experimentally-observed chain-like oxide ion ordering and hypothetical square ordering. (a) The melilite $\left[\mathrm{Ga}_{3} \mathrm{O}_{7}\right]$ framework projected along $00 l$, viewed as two interpenetrating hexagonal nets. Green $=\mathrm{Ga}$, red $=\mathrm{O}$. $(\mathrm{b}, \mathrm{c}) \mathrm{DFT}-\mathrm{relaxed} 1 \mathrm{x} 2 \mathrm{x} 1 P 1$ supercells of $\mathrm{La}_{2} \mathrm{Ga}_{3} \mathrm{O}_{7.5}$ with interstitial oxide arranged into chains or squares, overlaid with a fragment of the underlying hexagonal net. Green $=\mathrm{GaO}_{4}$, magenta $=\mathrm{GaO}_{5}$, blue $=\mathrm{La}$. (d) Derivation of the chain- and square orderings from antiparallel and parallel tilings of a single hexagonal tile. Note that parallel tiling (square ordering) imposes a special geometric constraint on the tile $\left(d=d^{\prime}\right)$, corresponding to a loss of $\left[\mathrm{Ga}_{3} \mathrm{O}_{7.5}\right]$ framework flexibility when compared to the antiparallel chain-ordered case.

The chain-like $\mathrm{O}_{\text {int }}$ ordering in $\mathrm{La}_{2} \mathrm{Ga}_{3} \mathrm{O}_{7.5}$ is consistent with the local occupancy rule proposed by $\mathrm{Li}$ et al. for $\mathrm{La}_{1.64} \mathrm{Ca}_{0.36} \mathrm{Ga}_{3} \mathrm{O}_{7.32}$, i.e. that the centres of the five pentagonal rings adjacent to $\mathrm{O}_{\text {int }}$ cannot themselves be occupied, due to the local strain produced by framework relaxation. ${ }^{18}$ However, chain-like ordering is not the only way to satisfy this rule: two- 
dimensional ordering (the square arrangement of $\mathrm{O}_{\text {int }}$ proposed by Li et al. $)^{18}$ provides an alternative model which is intuitive because it maximises the $\mathrm{O}_{\text {int }}-\mathrm{O}_{\text {int }}$ separation. The derivation of the chain- and square-orderings from this local occupancy rule is illustrated in Figure S6. To determine the relative stabilities of these two orderings in $\mathrm{La}_{2} \mathrm{Ga}_{3} \mathrm{O}_{7.5}$, we generated a $1 \times 2 \times 1$ supercell for each structure and relaxed them in $P 1$ symmetry by DFT (see Figure $4 b, c)$. This confirmed that chain-like ordering produces the most energetically favourable structure, with a difference of $0.44 \mathrm{eV}$ between the two models.
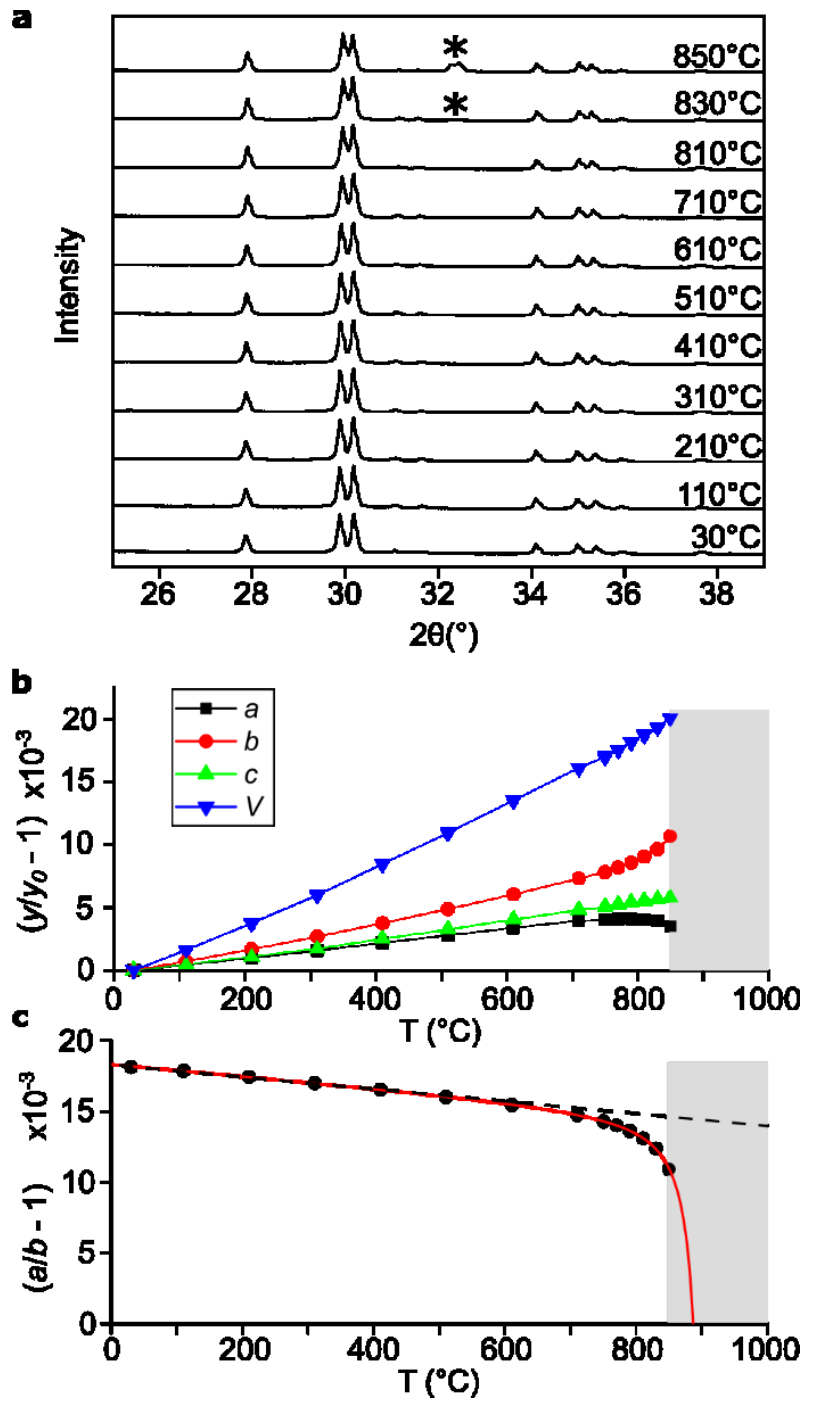

Figure 5: Structural trends in $\mathrm{La}_{2} \mathrm{Ga}_{3} \mathrm{O}_{7.5}$ on heating. (a) PXRD patterns collected on heating from $30-850^{\circ} \mathrm{C}$ showing the onset of decomposition to a perovskite phase (peaks marked with *) above $830^{\circ} \mathrm{C}$. (b) Relative trends in the lattice parameters, plotted as $y / y_{0}-1$ (where $y=a, b, c$ or $V$ and $y_{0}$ are their corresponding room temperature values). (c) Relative trend in the orthorhombicity of the unit cell, plotted as $a / b-1$, and fitted to a power law of form $f(T)=A-B \cdot T-\left(T_{C}-T\right)^{-C}$ (red line; see Table S3 for fitted values of $A, B, C$ and the critical temperature $\left.T_{C}\right)$. The black dashed line is a guide to the eye that follows the initial linear trend from $30^{\circ} \mathrm{C}$. The gray shaded areas in (b) and (c) indicate the region above the melilite decomposition temperature.

The difference between the stabilities of the two ordering models can be rationalized by representing the two dimensional $\left[\mathrm{Ga}_{3} \mathrm{O}_{7}\right]$ layer as a pair of interpenetrated hexagonal nets ("Cairo pentagonal tiling" or "MacMahon's Net") 43 as shown in Figure 4a. This means that the $\left[\mathrm{Ga}_{3} \mathrm{O}_{7}\right]$ layer can be considered as a hexagonal tiling, with a single tile whose vertices coincide with the $\mathrm{Ga}$ l atom positions. The tile contains four edgesharing pentagons as a motif (thus generating the orthogonal hexagonal net when tiled, as shown in Figure 4d). The inclusion of one interstitial oxide ion in the motif, at the center of one of the four pentagons generates the correct stoichiometry for the layer, $\left[\mathrm{Ga}_{3} \mathrm{O}_{7.5}\right]$. Finally, two edge-lengths $d$ and $d$ ' are defined,

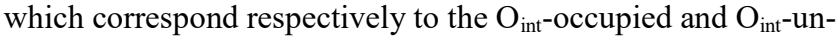
occupied halves of the hexagonal tile (Figure 4d). Using this tile, it is possible to generate the different orderings by antiparallel tiling (chain ordering) or parallel tiling (square ordering), as shown in Figure 4d.

Inspection of these tilings reveals that the two different ordered structures do not have the same freedom to distort locally. Specifically, parallel tiling (square ordering) is subject to a geometrical constraint that requires $d=d$ '. This places a constraint on the local geometry of the $\left[\mathrm{Ga}_{3} \mathrm{O}_{7.5}\right]$ framework, as confirmed by inspection of the $d$ and $d$ ' distances (Ga1 - Ga1) in the DFTrelaxed $P 1$ supercell, which are near-equal (6.337 and $6.338 \AA$, Figure 4c). In contrast, antiparallel tiling (chain ordering) is subject only to the general condition that the hexagonal tile have two parallel edges of equal length. Consequently, a distortion with $d \neq d$ ' is permitted, and inspection of these distances relaxed by DFT in $P 1$ confirms the occurrence of a local framework relaxation of this type (6.174 and $6.481 \AA$, Figure $4 b)$.

In summary, the chain-like ordering of $\mathrm{O}_{\text {int }}$ within the $\left[\mathrm{Ga}_{3} \mathrm{O}_{7.5}\right]$ layers of $\mathrm{La}_{2} \mathrm{Ga}_{3} \mathrm{O}_{7.5}$ results from the underlying hexagonal topology of the melilite framework, and allows the framework to have the maximum flexibility in response to the local strain produced by incorporation of these interstitial ions. In contrast, the two dimensional square ordering proposed on a local scale for $\mathrm{La}_{1.64} \mathrm{Ca}_{0.36} \mathrm{Ga}_{3} \mathrm{O}_{7.32}{ }^{18}$ would impose additional geometrical requirements which prevents the framework from relaxing fully when interstitial defects are introduced. These observations also cast new light on the complex partially-ordered structure of $\mathrm{La}_{1.64} \mathrm{Ca}_{0.36} \mathrm{Ga}_{3} \mathrm{O}_{7.32}$, as shown in Figure $\mathrm{S} 7$ which suggests that chain-like ordering is incipient in this compound.

Stability and structure at high temperature. We collected PXRD data at elevated temperatures to evaluate the thermal stability of $\mathrm{La}_{2} \mathrm{Ga}_{3} \mathrm{O}_{7.5}$. The compound was found to be stable below $830^{\circ} \mathrm{C}$ : above this temperature it begins to decompose into a mixture of $\mathrm{LaGaO}_{3}$ and $\mathrm{Ga}_{2} \mathrm{O}_{3}$ (Figure $5 \mathrm{a}$ ). $\mathrm{La}_{2} \mathrm{Ga}_{3} \mathrm{O}_{7.5}$ remains metrically orthorhombic throughout its stability range, in contrast to the orthorhombic melilites $\mathrm{La}_{1.64} \mathrm{Ca}_{0.36} \mathrm{Ga}_{3} \mathrm{O}_{7.32}$ and $\mathrm{La}_{1.64} \mathrm{Sr}_{0.36} \mathrm{Ga}_{3} \mathrm{O}_{7.32}$, which undergo a reversible phase transition to a disordered tetragonal polymorph on heating. ${ }^{18,19}$ An incipient phase transition of this type is evident in $\mathrm{La}_{2} \mathrm{Ga}_{3} \mathrm{O}_{7.5}$ as indicated by the trend in its basal lattice parameters $a$ and $b$ : extrapolation of the trend in $a / b$ ratio by fitting to a power law of form $f(T)=A-B . T-\left(T_{C}-T\right)^{-C}$ indicates a hypothetical phase transition temperature of $\sim 890^{\circ} \mathrm{C}$, which is higher than the decomposition temperature. However, the onset of this transition occurs at much lower temperatures, as suggested by the deviation from linearity in the range $610-710^{\circ} \mathrm{C}$ (Figure 5c). The thermal expansion coefficients calculated from the linear region $\left(\mathrm{T} \leq 610^{\circ} \mathrm{C}\right)$, shown in Table $\mathrm{S} 4$, are consistent with those reported for $\mathrm{La}_{1+\mathrm{x}} \mathrm{Sr}_{1-\mathrm{x}} \mathrm{Ga}_{3} \mathrm{O}_{7+\mathrm{x} / 2}$. $^{12}$

Conductivity. Figure 6 a shows the complex impedance plot of a $\mathrm{La}_{2} \mathrm{Ga}_{3} \mathrm{O}_{7.5}$ disk (obtained by polishing a bead) at $400^{\circ} \mathrm{C}$ in an oxygen atmosphere, which comprises one large semicircular arc and an inclined line. The large semicircular component of the 
high frequency arc displays capacitance $\sim 4-6 \mathrm{pF} \mathrm{cm}^{-1}$, and is ascribed to the bulk response, which can be simply modelled with a parallel resistor $\left(\mathrm{R}_{b}\right)$ and capacitor $\left(\mathrm{C}_{b}\right)$. The intercept of this arc at low frequency was extracted as bulk resistivity $\mathrm{R}_{\mathrm{b}}$ and the calculated capacitance $\mathrm{C}_{\mathrm{b}}$ is $\sim 4 \mathrm{pF} \mathrm{cm}^{-1}$ according to the equation $2 \pi f_{\max } \mathrm{RC}=1$ ( $f_{\max }$ is the frequency at maximum imaginary impedance $\left.Z^{\prime}{ }^{\prime}{ }_{\max }\right)$. This value is close to that calculated using the equation $\mathrm{M}{ }^{\prime}{ }_{\max }=\varepsilon_{0} / 2 \mathrm{C}\left(\mathrm{M}{ }^{\prime}{ }_{\max }\right.$ is the maximum imaginary modulus), confirming that the large semicircular arc is from the single bulk response. The inclined line in the low frequency region has capacitances ranging from $10^{-11} \mathrm{~F} \mathrm{~cm}^{-1}$ to 10 ${ }^{7} \mathrm{~F} \mathrm{~cm}^{-1}$ (inset of Figure 6a), suggesting heavily overlapping grain boundary and electrode response arcs. At high temperature, the bulk response arc gradually disappeared and the grain boundary and electrode response arcs became well resolved (see $700^{\circ} \mathrm{C}$ data, Figure $6 \mathrm{~b}$ ). The large capacitances $10^{-7} \sim 10^{-5}$ $\mathrm{F} \mathrm{cm}^{-1}$ for the electrode response arc suggest the occurrence of ionic conduction in $\mathrm{La}_{2} \mathrm{Ga}_{3} \mathrm{O}_{7.5}$.

Figure $6 \mathrm{c}$ shows the Arrhenius plot of bulk conductivities of $\mathrm{La}_{2} \mathrm{Ga}_{3} \mathrm{O}_{7.5}$. In the range $300-800{ }^{\circ} \mathrm{C}$, the bulk conductivity for $\mathrm{La}_{2} \mathrm{Ga}_{3} \mathrm{O}_{7.5}$ increases from $2.9 \times 10^{-8}-0.01 \mathrm{~S} \mathrm{~cm}^{-1}$, which is three orders of magnitude higher than the parent compound $\mathrm{LaSrGa}_{3} \mathrm{O}_{7}$. However, $\mathrm{La}_{2} \mathrm{Ga}_{3} \mathrm{O}_{7.5}$ is less conductive than

$\mathrm{La}_{1.54} \mathrm{Sr}_{0.46} \mathrm{Ga}_{3} \mathrm{O}_{7.27}$. Below $600^{\circ} \mathrm{C}$, the conductivity of $\mathrm{La}_{2} \mathrm{Ga}_{3} \mathrm{O}_{7.5}$ is three orders of magnitude lower than that for $\mathrm{La}_{1.54} \mathrm{Sr}_{0.46} \mathrm{Ga}_{3} \mathrm{O}_{7.27}$, and has an activation energy of $1.21(3) \mathrm{eV}$. At high temperatures above $600{ }^{\circ} \mathrm{C}$, the difference between conductivities of $\mathrm{La}_{2} \mathrm{Ga}_{3} \mathrm{O}_{7.5}$ and $\mathrm{La}_{1.54} \mathrm{Sr}_{0.46} \mathrm{Ga}_{3} \mathrm{O}_{7.27}$ reduces to approximately one order of magnitude, but the apparent activation energy of $\mathrm{La}_{2} \mathrm{Ga}_{3} \mathrm{O}_{7.5}$ increases to $1.62(2) \mathrm{eV}$. Although the VTPXRD data shows the incipient phase transition from orthorhombic to tetragonal starts at temperatures above $610{ }^{\circ} \mathrm{C}$, no typical abrupt jump in the conductivity was observed over the measured temperature region before the sample starts to decompose. We ascribe this behavior to a gradual thermally-induced disordering of oxide interstitials - a process that does not reach completion - which enhances the oxide ion conductivity and increases superficially the measured activation energy in the high temperature region. A lower activation energy region would be expected to appear in a higher temperature region for the hypothetical fully-disordered tetragonal phase if the material survived at such high temperatures: such behavior is exhibited in the well-defined phase transition region of $\mathrm{La}_{1.64} \mathrm{Ca}_{0.36} \mathrm{Ga}_{3} \mathrm{O}_{7.32}$ where a steeper gradient in the Arrhenius plot at $\sim 600^{\circ} \mathrm{C}$ links the low- and high-temperature plateaus associated with the orthorhombic and tetragonal phases respectively. ${ }^{18}$
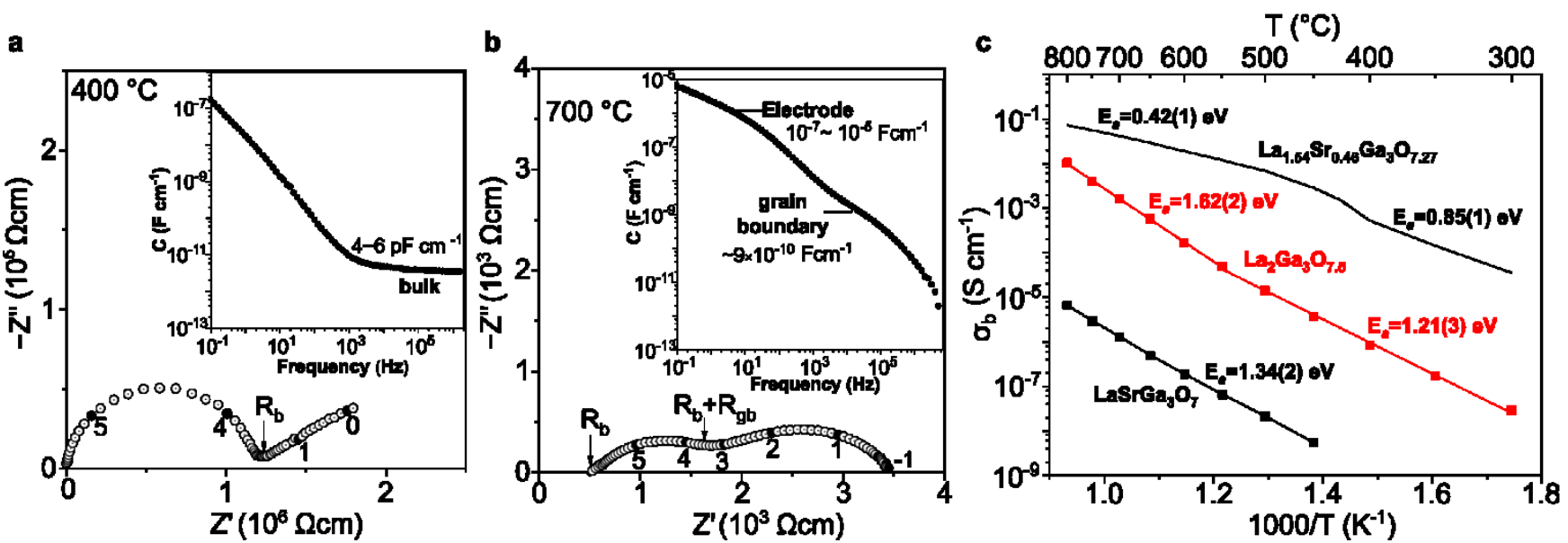

Figure 6. Complex impedance plots at (a) $400{ }^{\circ} \mathrm{C}$ and $700{ }^{\circ} \mathrm{C}$ of the $\mathrm{La}_{2} \mathrm{Ga}_{3} \mathrm{O}_{7.5}$ ceramic. $\mathrm{R}_{\mathrm{b}}$ and $\mathrm{R}_{\mathrm{b}}+\mathrm{R}_{\mathrm{gb}}$ denote the bulk and total resistivities, respectively. The inset in each part shows capacitance versus frequency plot. (c) Arrhenius plot of the bulk conductivities for $\mathrm{La}_{2} \mathrm{Ga}_{3} \mathrm{O}_{7.5}$ (red points) in comparison with those of $\mathrm{LaSrGa}_{3} \mathrm{O}_{7}$ (black points) and $\mathrm{La}_{1.54} \mathrm{Sr}_{0.46} \mathrm{Ga}_{3} \mathrm{O}_{7.25}$ (black line, data from reference 14).

\section{CONCLUSIONS}

A new ternary melilite compound $\mathrm{La}_{2} \mathrm{Ga}_{3} \mathrm{O}_{7.5}$ can be synthesized by direct crystallization of an under-cooled melt, showing that it is possible to exceed the long-established limit of interstitial oxide concentration in the melilite structure by selecting a suitable non-equilibrium synthesis method. $\mathrm{La}_{2} \mathrm{Ga}_{3} \mathrm{O}_{7.5}$ represents the end-member $(\mathrm{x}=1)$ of the $\mathrm{La}_{1+\mathrm{x}} A E_{1-\mathrm{x}} \mathrm{Ga}_{3} \mathrm{O}_{7+\mathrm{x} / 2}$ interstitial oxide ion conductor family, and is the first example of a ternary melilite compound. It adopts a unique anion-ordered superstructure with chain-like ordering of interstitial oxide ions, which is driven by the interplay between the local coordination requirements of the interstitial oxides and the underlying hexagonal topology of the $\left[\mathrm{Ga}_{3} \mathrm{O}_{7}\right]$ host framework.

$\mathrm{La}_{2} \mathrm{Ga}_{3} \mathrm{O}_{7.5}$ has a conductivity of $0.01 \mathrm{Scm}^{-1}$ at $800^{\circ} \mathrm{C}$ and is stable on heating up to $830^{\circ} \mathrm{C}$, putting it in the range of interest for solid oxide fuel cell devices. Despite the retention of long-range structural ordering up to its decomposition temperature, this is a reasonably high conductivity, three orders of magnitude above than that of the corresponding $\mathrm{x}=0$ end member $\mathrm{LaSrGa}_{3} \mathrm{O}_{7}$ and only one order of magnitude below that of $\mathrm{La}_{1.54} \mathrm{Sr}_{0.46} \mathrm{Ga}_{3} \mathrm{O}_{7.27}$. These observations will open the door to extended ranges of $\mathrm{La}_{1+\mathrm{x}} A E_{1-\mathrm{x}} \mathrm{Ga}_{3} \mathrm{O}_{7+\mathrm{x} / 2}$ melilite conductors with the potential for increasing conductivities in the $\mathrm{Ca}, \mathrm{Sr}$, Ba series, and may have a broader impact on related interstitial oxide conductor families such as the langasites and apatites, where the exploration of extended compositional ranges could lead to the discovery of new high-performance materials.

\section{ASSOCIATED CONTENT}

Supporting Information. Details of attempts to synthesize $\mathrm{La}_{2} \mathrm{Ga}_{3} \mathrm{O}_{7.5}$ by low temperature glass-crystallization; Figures $\mathrm{S} 1$ $\mathrm{S} 7$, Tables S1 - S4; crystallographic information file. This material is available free of charge via the Internet at http://pubs.acs.org.

\section{AUTHOR INFORMATION}

Corresponding Author 
* michael.pitcher@cnrs-orleans.fr

* mathieu.allix@cnrs-orleans.fr

\section{ACKNOWLEDGMENT}

Financial support from the CNRS (IR-RMN-THC Fr3050), the State Scholarship Fund of China Scholarship Council (201704910448), the Natural Science Foundation of China (No. 21622101), and Guangxi Natural Science Foundation (No. 2019GXNSFGA245006) are gratefully acknowledged. We thank the beamline staff at 11BM (APS, Argonne National Laboratory, USA) for collecting the SPD data via remote access, Dr. E. Suard (ILL, Grenoble, France) for performing the neutron diffraction experiment via EASY access, and Dr. E. Veron (CNRS, CEMHTI UPR3079, Orléans) for performing the in-house SEM-EDX measurements.

\section{REFERENCES}

(1) Wachsman, E. D.; Lee, K. T. Lowering the Temperature of Solid Oxide Fuel Cells. Science 2011, 334 (6058), 935-939.

(2) Kilner, J. A.; Burriel, M. Materials for Intermediate-Temperature Solid-Oxide Fuel Cells. Annu. Rev. Mater. Res. 2014, 44 (1), 365-393.

(3) Winborne, D. A.; Nordine, P. C.; Rosner, D. E.; Marley, N. F. Aerodynamic Levitation Technique for Containerless High Temperature Studies on Liquid and Solid Samples. Metall. Trans. $B$ 1976, 7 (4), 711-713.

(4) Benmore, C. J.; Weber, J. K. R. Aerodynamic Levitation, Supercooled Liquids and Glass Formation. Adv. Phys. X 2017, 2 (3), 717-736.

(5) Allix, M.; Alahrache, S.; Fayon, F.; Suchomel, M.; Porcher, F.; Cardinal, T.; Matzen, G. Highly Transparent $\mathrm{BaAl}_{4} \mathrm{O}_{7}$ Polycrystalline Ceramic Obtained by Full Crystallization from Glass. Adv. Mater. 2012, 24 (41), 5570-5575.

(6) Véron, E.; Garaga, M. N.; Pelloquin, D.; Cadars, S.; Suchomel, M.; Suard, E.; Massiot, D.; Montouillout, V.; Matzen, G.; Allix, M. Synthesis and Structure Determination of $\mathrm{CaSi}_{1 / 3} \mathrm{~B}_{2 / 3} \mathrm{O}_{8 / 3}$ : A New Calcium Borosilicate. Inorg. Chem. 2013, 52 (8), 42504258.

(7) Boyer, M.; Véron, E.; Becerro, A. I.; Porcher, F.; Suchomel, M. R.; Matzen, G.; Allix, M. $\mathrm{BaGa}_{4} \mathrm{O}_{7}$, a New $\mathrm{A}_{3} \mathrm{BC}_{10} \mathrm{O}_{20}$ Crystalline Phase: Synthesis, Structural Determination and Luminescence Properties. CrystEngComm 2015, 17 (32), 6127-6135.

(8) Boyer, M.; Yang, X.; Fernández Carrión, A. J.; Wang, Q.; Véron, E.; Genevois, C.; Hennet, L.; Matzen, G.; Suard, E.; Thiaudière, D.; Castro, C.; Pelloquin, D.; Kong, L. B.; Kuang, X.; Allix, M. First Transparent Oxide Ion Conducting Ceramics Synthesized by Full Crystallization from Glass. J. Mater. Chem. A 2018, 6 (13), 5276-5289.

(9) Ma, X.; Li, X.; Li, J.; Genevois, C.; Ma, B.; Etienne, A.; Wan, C.; Véron, E.; Peng, Z.; Allix, M. Pressureless Glass Crystallization of Transparent Yttrium Aluminum Garnet-Based Nanoceramics. Nat. Commun. 2018, 9 (1), 1175.

(10) Xu, J.; Wang, J.; Rakhmatullin, A.; Ory, S.; Fernández-Carrión, A. J.; Yi, H.; Kuang, X.; Allix, M. Interstitial Oxide Ion Migration Mechanism in Aluminate Melilite $\mathrm{La}_{1+\mathrm{x}} \mathrm{Ca}_{1-\mathrm{x}} \mathrm{Al}_{3} \mathrm{O}_{7+0.5 \mathrm{x}}$ Ceramics Synthesized by Glass Crystallization. ACS Appl. Energy Mater. 2019, 2 (4), 2878-2888.

(11) Yang, X.; Fernández-Carrión, A. J.; Wang, J.; Porcher, F.; Fayon, F.; Allix, M.; Kuang, X. Cooperative Mechanisms of Oxygen Vacancy Stabilization and Migration in the Isolated Tetrahedral Anion Scheelite Structure. Nat. Commun. 2018, 9 (1), 4484.

(12) Rozumek, M.; Majewski, P.; Schluckwerder, H.; Aldinger, F.; Künstler, K.; Tomandl, G. Electrical Conduction Behavior of $\mathrm{La}_{1+\mathrm{x}} \mathrm{Sr}_{1-\mathrm{x}} \mathrm{Ga}_{3} \mathrm{O}_{7-\delta}$ Melilite-Type Ceramics. J. Am. Ceram. Soc. 2004, 87 (9), 1795-1798.

(13) Zhou, L.; Xu, J.; Allix, M.; Kuang, X. Development of MeliliteType Oxide Ion Conductors. Chem. Rec. 2020 10.1002/tcr.202000069.

(14) Kuang, X.; Green, M. A.; Niu, H.; Zajdel, P.; Dickinson, C.; Claridge, J. B.; Jantsky, L.; Rosseinsky, M. J. Interstitial Oxide Ion Conductivity in the Layered Tetrahedral Network Melilite
Structure. Nat. Mater. 2008, 7 (6), 498-504.

Xu, J.; Li, Y.; Zhou, L.; Tang, X.; Kuang, X. Chemical Bonding Effect on the Incorporation and Conduction of Interstitial Oxide Ions in Gallate Melilites. Adv. Theory Simulations 2019, 2 (9), 1900069.

(16) Tealdi, C.; Mustarelli, P.; Islam, M. S. Energy Materials: Layered $\mathrm{LaSrGa}_{3} \mathrm{O}_{7}$-Based Oxide-Ion Conductors: Cooperative Transport Mechanisms and Flexible Structures. Adv. Funct. Mater. 2010, 20 (22), 3809-3809.

(17) Wei, F.; Gasparyan, H.; Keenan, P. J.; Gutmann, M.; Fang, Y.; Baikie, T.; Claridge, J. B.; Slater, P. R.; Kloc, C. L.; White, T. J. Anisotropic Oxide Ion Conduction in Melilite Intermediate Temperature Electrolytes. J. Mater. Chem. A 2015, 3 (6), 30913096.

(18) Li, M.-R.; Kuang, X.; Chong, S. Y.; Xu, Z.; Thomas, C. I.; Niu, H.; Claridge, J. B.; Rosseinsky, M. J. Interstitial Oxide Ion Order and Conductivity in $\mathrm{La}_{1.64} \mathrm{Ca}_{0.36} \mathrm{Ga}_{3} \mathrm{O}_{7.32}$ Melilite. Angew. Chemie Int. Ed. 2010, 49 (13), 2362-2366.

(19) Thomas, C. I.; Kuang, X.; Deng, Z.; Niu, H.; Claridge, J. B.; Rosseinsky, M. J. Phase Stability Control of Interstitial Oxide Ion Conductivity in the $\mathrm{La}_{1+\mathrm{x}} \mathrm{Sr}_{1-\mathrm{x}} \mathrm{Ga}_{3} \mathrm{O}_{7+\mathrm{x} / 2}$ Melilite Family. Chem. Mater. 2010, 22 (8), 2510-2516.

(20) Xu, J.; Wang, J.; Tang, X.; Kuang, X.; Rosseinsky, M. J. $\mathrm{La}_{1+\mathrm{x}} \mathrm{Ba}_{1-\mathrm{x}} \mathrm{Ga}_{3} \mathrm{O}_{7+0.5 \mathrm{x}}$ Oxide Ion Conductor: Cationic Size Effect on the Interstitial Oxide Ion Conductivity in Gallate Melilites. Inorg. Chem. 2017, 56 (12), 6897-6905.

(21) Diaz-Lopez, M.; Shin, J. F.; Li, M.; Dyer, M. S.; Pitcher, M. J.; Claridge, J. B.; Blanc, F.; Rosseinsky, M. J. Interstitial Oxide Ion Conductivity in the Langasite Structure: Carrier Trapping by Formation of $(\mathrm{Ga}, \mathrm{Ge})_{2} \mathrm{O}_{8}$ Units in $\mathrm{La}_{3} \mathrm{Ga}_{5-\mathrm{x}} \mathrm{Ge}_{1+\mathrm{x}} \mathrm{O}_{14+\mathrm{x} / 2}(0<\mathrm{x} \leq$ 1.5). Chem. Mater. 2019, 31 (15), 5742-5758.

(22) Boyer, M.; Carrion, A. J. F.; Ory, S.; Becerro, A. I.; Villette, S.; Eliseeva, S. V.; Petoud, S.; Aballea, P.; Matzen, G.; Allix, M. Transparent Polycrystalline $\mathrm{SrREGa}_{3} \mathrm{O}_{7}$ Melilite Ceramics: Potential Phosphors for Tuneable Solid State Lighting. J. Mater. Chem. C 2016, 4 (15), 3238-3247.

(23) Yoshimoto, K.; Masuno, A.; Ueda, M.; Inoue, H.; Yamamoto, H.; Kawashima, T. Low Phonon Energies and Wideband Optical Windows of $\mathrm{La}_{2} \mathrm{O}_{3}-\mathrm{Ga}_{2} \mathrm{O}_{3}$ Glasses Prepared Using an Aerodynamic Levitation Technique. Sci. Rep. 2017, 7, 45600.

(24) Weber, J. K. R. The Containerless Synthesis of Glass. Int. J. Appl. Glas. Sci. 2010, 1 (3), 248-256.

(25) Allix, M.; Hennet, L. Aerodynamic levitation https://www.cemhti.cnrs-orleans.fr/instruments/levitation.aspx (accessed Oct 2, 2020).

(26) Petrícek, V.; Dušek, M.; Palatinus, L. Crystallographic Computing System JANA2006: General Features. Zeitschrift fur Krist. 2014, 229 (5), 345-352.

(27) Rodrigues-Carvajal, J. FullProf Suite https://www.ill.eu/sites/fullprof/ (accessed Oct 2, 2020).

(28) Filik, J.; Ashton, A. W.; Chang, P. C. Y.; Chater, P. A.; Day, S. J.; Drakopoulos, M.; Gerring, M. W.; Hart, M. L.; Magdysyuk, O. V; Michalik, S.; Smith, A.; Tang, C. C.; Terrill, N. J.; Wharmby, M. T.; Wilhelm, H. Processing Two-Dimensional XRay Diffraction and Small-Angle Scattering Data in DAWN 2. J. Appl. Cryst 2017, 50, 959-966.

(29) Coelho, A. TOPAS Academic version $6 \mathrm{http}: / /$ www.topasacademic.net/ (accessed Oct 2, 2020).

(30) Segall, M. D.; Lindan, P. J. D.; Probert, M. J.; Pickard, C. J.; Hasnip, P. J.; Clark, S. J.; Payne, M. C. First-Principles Simulation: Ideas, Illustrations and the CASTEP Code. J. Phys. Condens. Matter 2002, 14 (11), 2717-2744.

(31) Clark, S. J.; Segall, M. D.; Pickard, C. J.; Hasnip, P. J.; Probert, M. I. J.; Refson, K.; Payne, M. C. First Principles Methods Using CASTEP. Zeitschrift fur Krist. 2005, 220 (5-6), 567-570.

(32) Perdew, J. P.; Burke, K.; Ernzerhof, M. Generalized Gradient Approximation Made Simple. Phys. Rev. Lett. 1996, 77 (18), 3865-3868.

(33) Yates, J. R.; Pickard, C. J.; Mauri, F. Calculation of NMR Chemical Shifts for Extended Systems Using Ultrasoft Pseudopotentials. Phys. Rev. B 2007, 76 (2), 24401.

(34) Pfrommer, B. G.; Côté, M.; Louie, S. G.; Cohen, M. L. Relaxation of Crystals with the Quasi-Newton Method. J. Comput. Phys. 1997, 131 (1), 233-240.

(35) Profeta, M.; Mauri, F.; Pickard, C. J. Accurate First Principles 
Prediction of 17O NMR Parameters in SiO2: Assignment of the Zeolite Ferrierite Spectrum. J. Am. Chem. Soc. 2003, 125 (2), 541-548.

(36) Pickard, C. J.; Mauri, F. All-Electron Magnetic Response with Pseudopotentials: NMR Chemical Shifts. Phys. Rev. B 2001, 63 (24), 245101.

(37) Gan, Z. Isotropic NMR Spectra of Half-Integer Quadrupolar Nuclei Using Satellite Transitions and Magic-Angle Spinning. $J$. Am. Chem. Soc. 2000, 122 (13), 3242-3243.

(38) Kwak, H.-T.; Gan, Z. Double-Quantum Filtered STMAS. J Magn. Reson. 2003, 164 (2), 369-372.

(39) Massiot, D.; Fayon, F.; Capron, M.; King, I.; Le Calvé, S.; Alonso, B.; Durand, J.-O.; Bujoli, B.; Gan, Z.; Hoatson, G. Modelling One- and Two-Dimensional Solid-State NMR Spectra. Magn. Reson. Chem. 2002, 40 (1), 70-76.

(40) King, I. J.; Fayon, F.; Massiot, D.; Harris, R. K.; Evans, J. S. O. A Space Group Assignment of $\mathrm{ZrP}_{2} \mathrm{O}_{7}$ Obtained by ${ }^{31} \mathrm{P}$ Solid State
NMR. Chem. Commun. 2001, 18, 1766-1767.

Martineau, C.; Fayon, F.; Suchomel, M. R.; Allix, M.; Massiot, D.; Taulelle, F. Structure Resolution of $\mathrm{Ba}_{5} \mathrm{Al}_{3} \mathrm{~F}_{19}$ and Investigation of Fluorine Ion Dynamics by Synchrotron Powder Diffraction, Variable-Temperature Solid-State NMR, and Quantum Computations. Inorg. Chem. 2011, 50 (6), 2644-2653.

(42) Amoureux, J.-P.; Huguenard, C.; Engelke, F.; Taulelle, F. Unified Representation of MQMAS and STMAS NMR of Half-Integer Quadrupolar Nuclei. Chem. Phys. Lett. 2002, 356 (5), 497-504.

(43) O'Keeffe, M.; Hyde, B. G. Plane Nets in Crystal Chemistry. Philos. Trans. R. Soc. London. Ser. A, Math. Phys. Sci. 1980, 295 (1417), 553-618. 


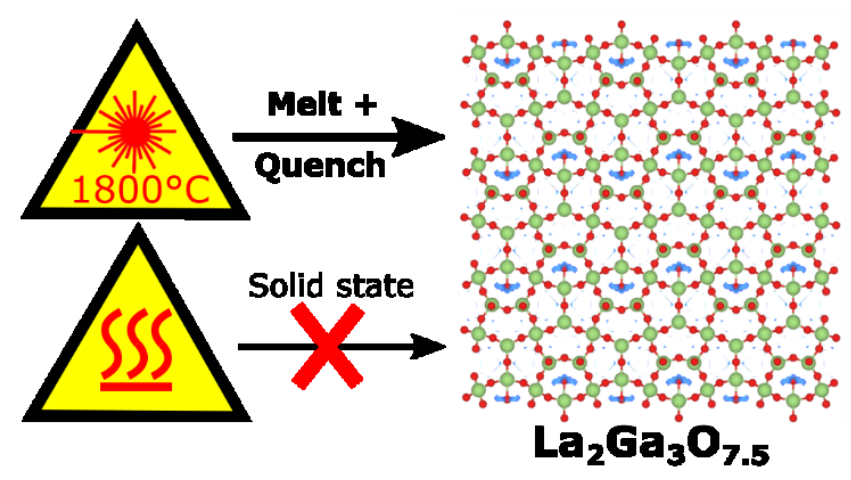

